\title{
Design Considerations to Optimise Supercapacitor-based Energy Storage Systems for Aerospace Applications
}

\author{
Ahmed Fares \\ Department of Electrical and Electronic \\ Engineering, \\ University of Nottingham, \\ Nottingham, United Kingdom \\ National Authority for Remote Sensing \\ and Space Sciences, \\ Cairo, Egypt \\ ahmed.fares@nottingham.ac.uk
}

\author{
Christian Klumpner \\ Department of Electrical and Electronic \\ Engineering, \\ University of Nottingham, \\ Nottingham, United Kingdom \\ klumpner@ieee.org
}

\author{
Mohamed Rashed \\ Department of Electrical and Electronic \\ Engineering, \\ University of Nottingham, \\ Nottingham, United Kingdom \\ mohamed.rashed@nottingham.ac.uk
}

\begin{abstract}
This paper investigates the design optimization of a supercapacitor-based energy storage system for aerospace applications which may be needed to complement the operation of a high power pulsed load such as electromechanical actuators have been proposed. Different designs of a supercapacitor (SC) stack to achieve minimum weight are investigated but this may cause suboptimal operation of the associated converter. To assess the impact on the weight of the converter, the weight of its key elements are assessed and shown that at system level an optimal solution can be found. Thermal stress analysis on the candidate supercapacitor cells is investigated to ensure the design solutions are valid.
\end{abstract}

Keywords - Electrical energy storage system, optimization, supercapacitors

\section{INTRODUCTION}

It is predicted that in new aircraft designs, significantly more electrical power will be generated and consumed, a trend referred to as "more Electric Aircraft". Some of this equipment, such as flight actuation is characterised by significant peak power requirement which will cause significant challenges for the power system affecting its ratings and stability. This may cause difficulties to the power system especially when it needs to deliver the peak load power requirement or when the highly dynamic loads cause rapid electrical transients that can cause voltage disturbances[1].

There are two options to address this issue: (i) increasing the rated power for the on-board power generation system in conjunction with decreasing the impedance/resistance of the power bus which requires the increase of the crosssection/weight of the cables or (ii) the use of energy storage to compensate for the high power peaks that are characteristic to an intermittent power consumption.

Employing energy storage may allow changes in the design of the power system for more electric aircrafts. For example, the generation system will be designed to provide the average power consumption of the overall system, while energy storage provides the power peaks and hence reducing the size of the generation units and the engine stress. Also, Local/ distributed energy storage may be considered to smooth the power demand surges of a specific loads with pulsed power demand nature such as EMAs. This will allow reducing the cross-section of the power cables in accordance to the average power consumption of the EMAs, rather than the peak power/current requirement.. Some advantages may be also gained if in new aircraft designs, weight reduction is implemented by adapting the cross-section of the power cables in accordance with the average power consumption, rather than the peak power/current requirement. Different technologies of storing energy exist and their characteristics need to be assessed against the requirement from the application. Aircraft applications are characterised by a need to provide minimum weight which translates in high specific energy $(\mathrm{Wh} / \mathrm{kg})$ and specific power $(\mathrm{kW} / \mathrm{kg})$, which is needed to minimise system weight and high round-trip efficiency which is needed to minimise fuel consumption, whilst minimising the cost is not a prime concern. It is widely recognised that electrochemical energy storage is the only suitable technology for aircraft use. There are two representative devices that each offer high specific energy (Lithium-ion battery offer approx. $100-300 \mathrm{Wh} / \mathrm{kg}$ ) or high specific power (the Electrochemical Double Layer Capacitor (EDLC) referred also as supercapacitor (SC) which offer $5-20 \mathrm{~kW} / \mathrm{kg}$ but at a specific energy of less than 5$10 \mathrm{Wh} / \mathrm{kg}$ )[2]. This makes the selection of the suitable electrochemical energy storage device highly dependent on the specific of the applications, with centralised energy storage systems designed to store large amounts of energy can also deliver powers of similar magnitude as the generator ratings and would favour the use of Li-ion batteries whilst distributed energy storage systems needed to compensate for a very particular high peak power/short term loads will favour the use of supercapacitors [3].

This paper will investigate the design of a supercapacitor based local energy storage system for high peak power loads. Based on the technical specification, a set of commercially available supercapacitor devices are selected. It will be shown that there is significant variation in the specific energy offered by the different devices which leads to different implementations that result in a trade-off between supercapacitor weight and the current 
rating of the required $\mathrm{DC} / \mathrm{DC}$ converter. This is caused by the fact that small capacity SC devices that have lower specific energy will result in higher number of series connected cells, higher SC stack voltages and lower maximum current/converter weight whilst some of the largest cells will provide better specific energy/lower weight but due to lower SC string voltage will result in larger current ratings and converter weight. The paper will investigate the weight of the SC-unit and converter components and the resulting losses for the shortlisted designs and will investigate the thermal stress on the SCcells under theses designs based on accurate loss models for the used cells to demonstrate how an optimum energy storage system implementation can be achieved.

\section{SUPERCAPACITOR UNIT SIZING}

A supercapacitor energy storage system (SC-ESS) shown in Fig. 1, consists of a supercapacitor (SC) unit and a DC$\mathrm{DC}$ converter interfacing the SC unit to the DC-bus.

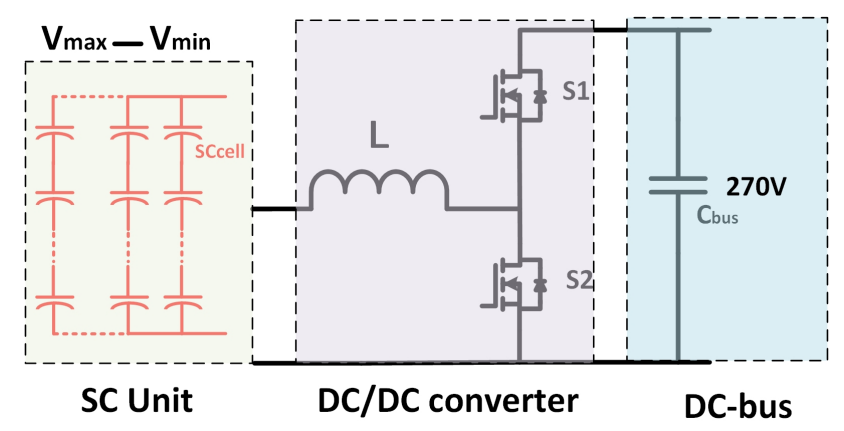

Fig. 1 supercapacitor energy storage system block diagram

The SC unit can be implemented as series/parallel combinations of supercapacitor cells to provide the required voltage level as well as energy capacity. The design of the SC-unit in this paper should satisfy the energy and power requirements of the given load as listed in TABLE 1.

\begin{tabular}{|l|l|}
\multicolumn{1}{c}{ TABLE 1 SC-ESS REQUIREMENTS } \\
\hline Maximum power & $2 \mathrm{~kW}$ \\
\hline Bus voltage & $270 \mathrm{~V}$ \\
\hline Energy capacity & $10 \mathrm{Wh}$ \\
\hline
\end{tabular}

Based on these requirements, the equivalent capacitance of the SC-unit can be estimated as:

$$
C_{e q}=\frac{2 E_{s t r}}{\left(V_{\max }^{2}-V_{\min }^{2}\right)}
$$

Where $E_{s t r}$ is the targeted energy capacity (Joules), $V_{\max }$ and $V_{\min }$ are the maximum and minimum voltage for the $\mathrm{SC}$-unit. The minimum voltage is usually selected to be around $50 \%$ of the maximum voltage to limit the SC-unit current for the required power which has direct impact on size/weight of magnetics/semiconductors. Accordingly, the required capacitance of a single SC-cell in the string can be estimated as:

$$
\text { Ccell }=\frac{\text { Ceq. } V_{\max }}{V_{\text {cell }}}
$$

Where $V_{\text {cellmax }}$ is the maximum operating voltage of the SC-cell that should be slightly lower than the specified maximum value from manufacturer $(2.7 \mathrm{~V}$ for most $\mathrm{SC}$ cells) to allow a safety margin in the design. This capacitance can be achieved either directly using single cell or by parallel combination of two or more cells based on the available standard capacitances.

Ideally, the design of SC-unit is to select $V_{\max }$ to be as high as the bus voltage (in this case $270 \mathrm{~V}$ ) to minimize the converter current ratings, then as the SC-unit discharges and its voltage decreases, the DC-DC converter adapts its duty cycle to maintain SC-ESS power at the designated value [4-6].

By applying (1)-(2) to the design requirements in Table 1, the desired SC-cell capacity is determined to be $150 \mathrm{~F}$ but as the converter could accommodate lower stack voltages which would require less series connected cells of higher capacitance. This means that the $150 \mathrm{~F}$ cell represents the lowest cell capacitance (although this could be implemented as parallel connection of multiple cells). In order to identify the best SC device, the characteristics of commercially available SC cells within a capacity range of $100-400 \mathrm{~F}$ is evaluated from the point of view of specific energy $(\mathrm{Wh} / \mathrm{kg})$ as it will reflect the overall weight of the SC-unit. As it can be observed from Fig. 2, the specific energy varies quite a lot due to manufacturing/cost saving limitations. The actual $150 \mathrm{~F}$ SC-cell that matches the design calculations based on (1)(2) is not the most energy dense device in the considered range as it has low specific energy $(4.7 \mathrm{Wh} / \mathrm{kg})$ compared to the Maxwell 350F cell that has a significantly higher specific energy of $5.9 \mathrm{Wh} / \mathrm{kg}(+25 \%)$ but using a larger cell will require fewer series connected devices that will lower the stack voltage and will increase the converter current/weight..

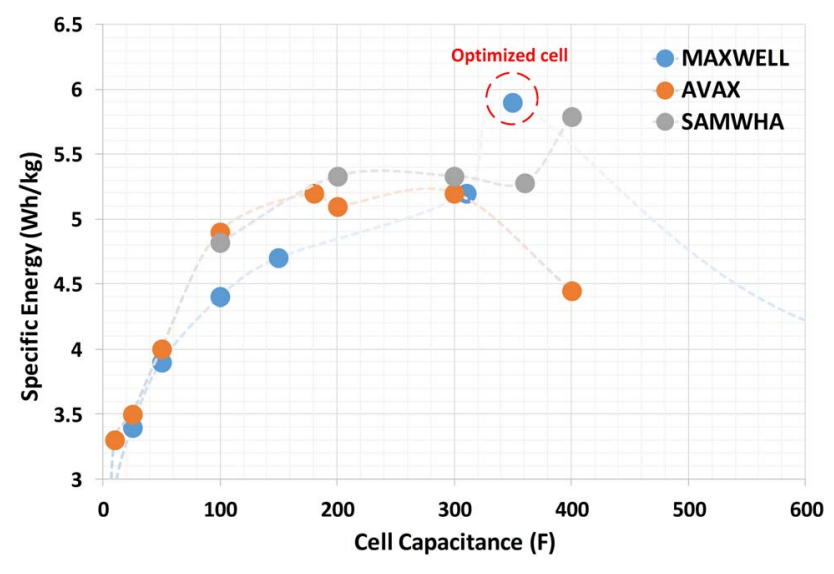

Fig. 2 Specific energy vs actual cell capacity for a range of SC cells

Alternatively, designing the SC-unit with $\left(V_{\max }=220 \mathrm{~V}\right)$ results in utilization of $180 \mathrm{~F}$ capacity SC-cell with better specific energy $(+13 \%)$ compared to the $150 \mathrm{~F}$ capacity SCcell which results in weight reduction of the SC-unit. Fig. 3 shows the utilized SC-cell's capacity and accordingly the overall SC-unit's weight for different designs of SC-unit's maximum voltage. It can be observed that the overall weight of the SC-unit based on the $150 \mathrm{~F}$ cell design $\left(V_{\max }=270 \mathrm{~V}\right)$ is $3.4 \mathrm{~kg}$. However, when designing the SC- 
unit with the $350 \mathrm{~F}$ cells $\left(V_{\max }=110 \mathrm{~V}\right)$, the overall weight of the SC-unit is $2.7 \mathrm{~kg}$ which is $25 \%$ less compared to the previous design. On the other hand, reducing SC-unit's voltage under the same power requirement results in increasing the current requirements which in turns may increase power losses inside SC-cells and the thermal stress which are attenuated by the fact that larger devices have lower resistance and capability to dissipate more losses. Also, reduced voltage of the SC-unit adds more challenges for the interfacing DC-DC converter in terms of lower efficiency at minimum voltage of SC-unit $\left(V_{\min }\right) /$ maximum boosting ratio (gain) as well as needing larger current capability which increases the converter weight.

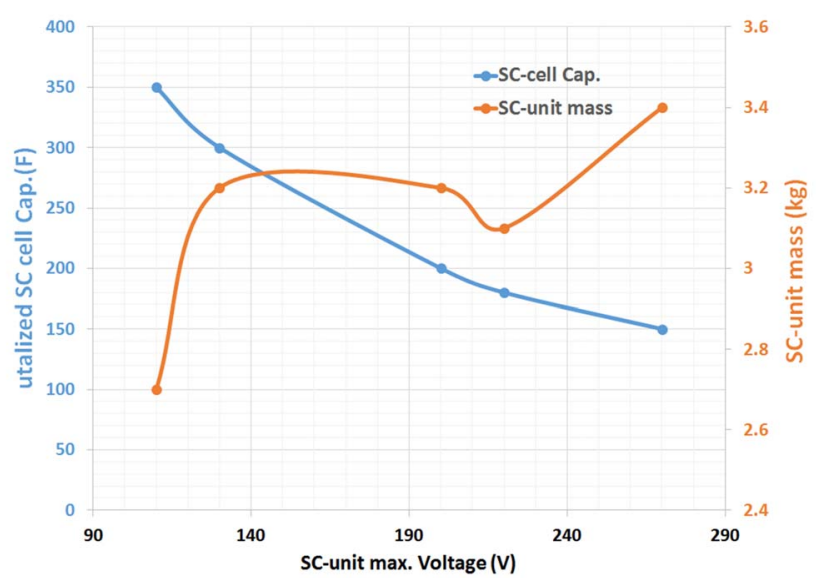

Fig. 3 Comparison of SC-cell capacitance and SC-unit mass at different designs of SC-unit voltage

Fig. 4 shows the maximum current of the SC-unit and the maximum voltage gain requirements for the converter for different designs of SC-unit. As can be observed, for the weight minimized design of the SC-unit with $\left(V_{\max }=110 \mathrm{~V}\right)$, the converter gain at $V_{\text {min }}=55 \mathrm{~V}$ should be 5 which leads to a significant increased converter weight which in turn may undermine the weight savings obtained in the SC-unit design. For this reason, it is necessary to estimate the impact on system weight of the design of the interfacing converter.

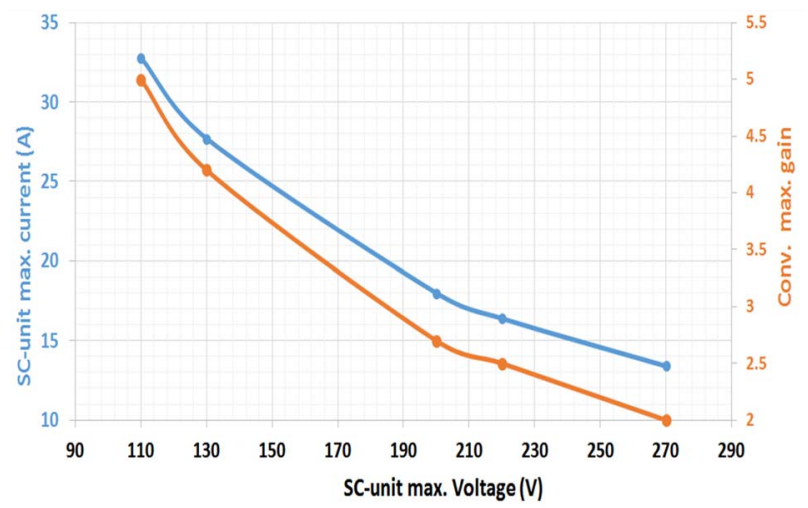

Fig. 4 SC-unit current and Conv. gain at diff. designs

\section{INTERFACING DC-DC CONVERTER ANALYSIS}

First, the use of a traditional half bridge DC/DC converter configuration is considered, to get an indication of how the SC-unit design will influence the weight of the inductor. Then a more complex converter arrangements such as paralleled interleaved that offer the possibility to further reduction of the overall weight of passive components is considered. As the interfacing DC-DC converter works in boost mode, the inductance of the inductor can be estimated at worst operating point $(50 \%$ duty cycle):

$$
L=\frac{V_{b u s}}{4 . \Delta I \cdot f_{S}}
$$

Where $V_{b u s}$ is the bus voltage $(270 \mathrm{~V}), \Delta I$ is the inductor current ripple and $f_{s}$ is the switching frequency. As $V_{b u s}$ and $f_{s}$ are same for all SC unit designs, it is clear that the required inductance is determined by the maximum ripple current that is usually specified as proportion of rated/maximum current, which is inverse proportional to the maximum/minimum SC unit voltage. On the other hand, in order to maintain the copper power losses at designated level at the increased average inductor current a thicker winding wire may be required in order to reduce the DC resistance which increases the inductor weight as shown hereafter.

\section{A. Inductor size}

As the inductor is one of the main contributors to the converter weight, the estimation of the inductor weight will be used in this investigations as an indicator for the overall converter's weight Inductor design for the interfacing DC$\mathrm{DC}$ converter under SC-unit with maximum voltage of $270 \mathrm{~V}$ (higher voltage (HV) design) and $110 \mathrm{~V}$ (lower voltage (LV) design) are shown in TABLE 2. The inductor designs are based on Kool $\mathrm{M} \mu \AA$ Cores with the shown part numbers and all the designs are based on using $100 \mathrm{kHz}$ switching frequency; faster switching would allow further weight reduction but that will influence all SC unit designs in the same proportion. For the converter interfacing the HV SC-unit, the maximum DC current of the inductor ( $\mathbf{I}_{\mathbf{D C}-}$ $\max )$ is $14.8 \mathrm{~A}$, and the required inductance is $244 \mu \mathrm{H}$. Accordingly, the core weight of the inductor is $120 \mathrm{~g}$ and the weight of the copper winding is $180 \mathrm{~g}$ giving an overall inductor weight of $300 \mathrm{~g}$. On the other hand, reducing the maximum voltage for the LV SC-unit to $110 \mathrm{~V}$ increased $\mathbf{I}_{\mathbf{D C}-\max }$ to $36.4 \mathrm{~A}$, although this increase in the inductor current reduces the required inductance to $93 \mu \mathrm{H}$ to maintain the same current ripple percentage of $\mathbf{I}_{\mathbf{D C} \text {-max }}$, the wire diameter for winding increased significantly to keep copper losses constant. As a result, the copper weight become the main contributor of the inductor weight (344g) compared to the core mas of $(140 \mathrm{~g})$ resulting in an overall inductor weight of $484 \mathrm{~g}$ which results in an increased inductor weight of $60 \%$ compared to HV SC-unit design.

Although the LV SC-unit design saved $700 \mathrm{~g}$ in terms of SC-unit's weight compared to HV SC-unit as described in $\S \mathrm{II}$, it will require an inductor that is $184 \mathrm{~g}$ heavier but overall, the LV SC-unit design is still providing weight reduction, although the impact of having higher losses on added weight has not been considered.

In order retain as much of the SC-unit weight savings, a superior interfaced converter topology need to be considered that will facilitate smaller magnetics. Compared to the standard topology, the two channel interleaved converter (Fig. 5) for interfacing the LV SCunit needs two inductors but rated at half the $\mathrm{SC}$ current 
which means thinner conductor used in the winding. The interleaving between the two channels results in ripple cancelation seen in the SC current and this allows for significantly higher inductor current ripple to be used which means the inductance L1/2 can be relatively small. TABLE 2 shows the input and output design parameters for the converter inductors for three SC\&converter configurations: single channel HV and LV SC units and LV-2ch interleaved. The weight reduction offered by the two channel interleaved converter is very clear: the core weight of each inductor is $63 \mathrm{~g}$ so the overall core weight is $126 \mathrm{~g}$ compared to $140 \mathrm{~g}$ for the single channel converter. Similarly, the overall copper weight for the two inductors in the interleaved converter is $236 \mathrm{~g}$ compared to $344 \mathrm{~g}$ in the single channel converter. This gives an overall weight for the inductors for the interleaved converter of $364 \mathrm{~g}$ ($25 \%$ ) compared to $484 \mathrm{~g}$ for the single channel one. When comparing weight of the two channel interleaved converter designed for LV SC-unit with the single channel HV SCunit, it could be concluded that it results in only $64 \mathrm{~g}$ extra weight which means the power density degradation of the converter due to higher load current is significantly reduced by using interleaving (although it is true, that using an interleaved converter for the HV-SC unit could further improve its power density as well). It can be concluded that these weight predictions for the inductor weight are confirming that the savings in the weight of SC cells $(-700 \mathrm{~g})$ in the LV design is more significant than the added inductor weight which means that the system optimisation will be driven mainly by the need to utilise the $350 \mathrm{~F}$ cells.

TABLE 2 INDUCTOR DESIGN FOR INTERFACING CONVERTER

\begin{tabular}{|c|c|c|c|}
\hline \multirow[b]{2}{*}{$\begin{array}{l}\text { Inductor } \\
\text { parameters }\end{array}$} & \multicolumn{3}{|c|}{ SC-Unit design } \\
\hline & HV-1ch & LV - 1ch & $\begin{array}{c}\text { LV } \\
\text { 2ch-interl. }\end{array}$ \\
\hline $\mathbf{I}_{\mathrm{DC}-\max }(\mathrm{A})$ & 14.8 & 36.4 & 18.2 \\
\hline $\begin{array}{l}\text { Current Ripple } \\
\%\left(I_{\text {DC-max }}\right)\end{array}$ & 20 & 20 & 50 \\
\hline Inductance $(\mu \mathrm{H})$ & 244 & 93 & 75 \\
\hline Core part No. & $00 \mathrm{k} 5528 \mathrm{e} 026$ & $00 \mathrm{k} 7228 \mathrm{e} 026$ & $00 \mathrm{k} 4022 \mathrm{e} 026$ \\
\hline Core weight & $120 \mathrm{~g}$ & $140 \mathrm{~g}$ & $63 \mathrm{~g}$ \\
\hline No. of turns & 54 & 34 & 31 \\
\hline Wire Size(AWG) & 12 & 8 & 11 \\
\hline $\operatorname{DCR}(\mathrm{m} \Omega)$ & 32 & 9.5 & 13.8 \\
\hline Copper losses & $6.4 \mathrm{~W}$ & $12 \mathrm{~W}$ & $4.5 \mathrm{~W}$ \\
\hline Copper weight & $180 \mathrm{~g}$ & $344 \mathrm{~g}$ & $118.7 \mathrm{~g}$ \\
\hline Overall weight & $300 \mathrm{~g}$ & $484 \mathrm{~g}$ & $363.5 \mathrm{~g}$ \\
\hline
\end{tabular}

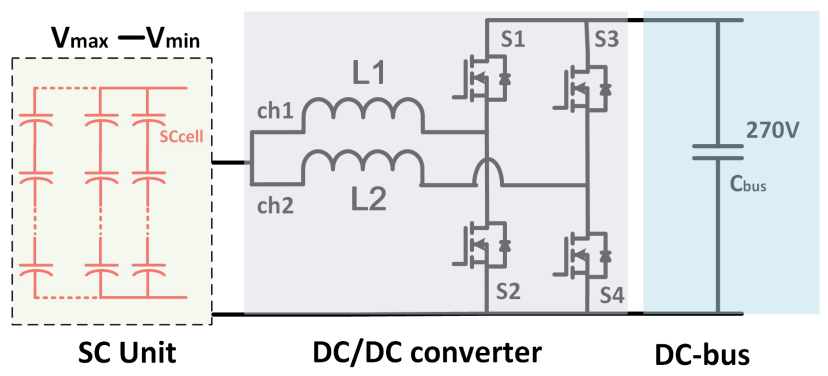

Fig. 5 Two channels interleaved converter

\section{B. Converter efficiency}

The efficiency of the converter can be estimated based on the calculation of the losses for each key system component which are inductor copper losses and semiconductor switching and conduction losses. The inductor core losses are neglected in this study assuming that the best core material is used and that the inductor DC current component imposes a permanent bias on the B-H curve and that the current ripple causes only minor hysteresis losses.

The inductor copper losses can be approximated by neglecting the AC-component of the losses as:

$$
P_{\text {copper }}=I^{2} r m s . D C R
$$

Where $D C R$ is the DC-resistance of the inductor windings and $I_{r m s}$ is the inductor RMS current which can be calculated as:

$$
I_{r m s}=\sqrt{I^{2}+\frac{\Delta I^{2}}{12}}
$$

Where $I$ is the DC inductor current and $\Delta I$ is the peak-topeak value of ripple current. The second part of the losses is the switches (MOSFETs) losses which is divided into the conduction and switching losses that can be estimated according to [7] as follows:

$$
P_{\text {cond }}=I^{2} r m s \cdot R_{d s-o n}
$$

Where $R_{d s-o n}$ is the drain-source resistance during ON-state of the switch, same for both the upper or lower switch in the converter leg as identical devices are used. The switching energy loss reaches a significant level during the commutation as current through device (I) and voltage across it (Vbus) overlap. An average power loss can be determined as:

$$
P_{s w}=\frac{V_{b u s} \cdot I}{2}\left(t_{d-o n}+t_{d-o f f}\right) f_{S}
$$

Where $V_{\text {bus }}$ is the bus voltage, $t_{d \text {-on }}$ and $t_{d \text {-off }}$ represent the ON and OFF delay times of the switch respectively, and $f_{s}$ is the switching frequency.

TABLE 3 shows the efficiency calculation for the interfacing converter for three different designs of SC-unit. The voltage stress for the switches for all converters is $270 \mathrm{~V}$ (Vbus) and the switching frequency considered for all design is $100 \mathrm{kHz}$. For the HV SC-unit, inductor peak current is $\approx 17 \mathrm{~A}$. The best switch matching this rating has been selected and the efficiency has been calculated under maximum current condition as $95.9 \%$. The second option is the single channel converter interfacing the LV SC-unit and the inductor peak current this case is $\approx 43 \mathrm{~A}$ and accordingly the best switch for this range has been selected and the efficiency at maximum load estimated but at a significantly lower level of $86.6 \%$ due to the high current stress of the converter under low voltage. The third option is the two channel interleaved converter interfacing the LV SC-unit for which a better switch technology $(\mathrm{GaN})$ actually exists. It is true that two of these devices could have been used in parallel for option 2 to improve its efficiency but having to use same semiconductors (type, number) would make inductor size as an undeniable advantage and this is why this has not been evaluated. The current ratting of the devices is reduced compared to the single channel converter, also due to the significantly 
better performance of the GaN devices, both in conduction loss (20W compared to $117 \mathrm{~W})$ and switching (6W compared to $99 \mathrm{~W})$, the efficiency of the two channel interleaved converter reached $95.3 \%$ which is very close to the efficiency of the converter interface for the HV SCunit. This means that the cooling requirement for option 1 and 3 converters is very similar and an assumption that these will offer similar power density is valid. This means combining the benefits of the LV SC-unit weight reduction without paying any penalties in terms of converter weight or efficiency. However, the thermal stress on the SC-cells due to the high current under low voltage design would be higher and this is investigated in the following section.

TABLE 3 CONVERTER EFFICIENCY AT DIFFERENT DESINGS

\begin{tabular}{|l|c|c|c|}
\hline \multirow{2}{*}{ parameters } & \multicolumn{3}{|c|}{ SC-Unit design } \\
\cline { 2 - 4 } & HV-1ch & LV 1ch & $\begin{array}{c}\text { LV 2ch- } \\
\text { interleaved }\end{array}$ \\
\hline $\begin{array}{l}\text { Switch -part } \\
\text { number }\end{array}$ & IXFH 30N40Q & APT40M90JN & GS66508B \\
\hline $\begin{array}{l}\text { Switch- } \\
\text { technology }\end{array}$ & Si MOSFET & Si MOSFET & eGAN FET \\
\hline $\mathbf{V}_{\text {DS }}(\mathbf{V})$ & 400 & 400 & 650 \\
\hline $\mathbf{I}_{\mathbf{d s}}(\mathbf{A})$ & 30 & 51 & 30 \\
\hline $\mathbf{R}_{\text {DS-on }}(\mathbf{m} \mathbf{\Omega})$ & 160 & 90 & 63 \\
\hline $\mathbf{t}_{\text {d-on }}(\mathbf{n S e c})$ & 25 & 32 & 4.3 \\
\hline $\mathbf{t}_{\mathbf{d}-\text { off }}(\mathbf{n S e c})$ & 51 & 70 & 8.2 \\
\hline $\mathbf{P}_{\text {cond }}(\mathbf{W})$ & 31 & 117 & 20 \\
\hline $\mathbf{P}_{\text {Sw }}(\mathbf{W})$ & 28 & 99 & 6 \\
\hline Efficiency \% & 95.9 & 86.6 & 95.3 \\
\hline
\end{tabular}

\section{EVAlUATION OF SUPERCAPACITOR CELlS}

In order to accurately evaluate the thermal stress on the SC-cells, accurate electrical and thermal models are required to accurately estimate the power losses inside the candidate SC cells and accordingly the thermal stresses.

\section{A. Deriving the electrical model}

The equivalent circuit model (ECM) is used here to represent the behaviour of the $\mathrm{SC}$ cell giving more importance to extracting the correct internal resistances and neglecting the leakage current as the scope of the model is to evaluate the thermal stress during charge/discharge cycling. In order identify the behaviour of the SC-cell, an experimental characterization through electrochemical impedance spectroscopy (EIS) has been performed on the selected cells using the Biologic $\AA$ SP150 potentiostat. EIS testing results for the Maxwell 350F SC-cell within a frequency range of $50 \mathrm{mHz}$ to $10 \mathrm{kHz}$ and at different bias voltages are shown in Fig. 6. It can be seen that the cell resistance is changing with frequency as well as bias voltage (equivalent to state of charge). The changing in SC-cell resistance with bias voltage is less significant, so a good approximation can be achieved by considering the operating voltage range of the $\mathrm{SC}$ cell ( $1.25 \mathrm{~V}$ to $2.5 \mathrm{~V}$ in this design), so resistance at $2 \mathrm{~V}$ which is close to cycle average can be used leading to ESR errors of $\max 5 \%$ On the other hand, changing of SC-cell's resistance with frequency is significant, the resistance at 50 $\mathrm{mHz}$ is $100 \%$ more compared to the resistance at $50 \mathrm{~Hz}$, so it cannot be approximated accurately by a single average value. Thus, the simplified ECM consisting of a resistor (ESR) in series with the bulk capacitor shown in Fig. 7 (a) is not accurate for detailed loss estimations where the particularities of the load cycle are available [8].
Modelling the observed behaviour of the SC cell resistance accurately requires a dynamic model with $n$ number of $\mathrm{R} / / \mathrm{C}$ branches as shown in Fig. 7 (b). Increasing the number of $\mathrm{R} / / \mathrm{C}$ branches increases the accuracy of the model but increases the model complexity, Fig. 8 shows the accuracy of fitting the SCcell EIS with $5^{\text {th }}$ order ECM.

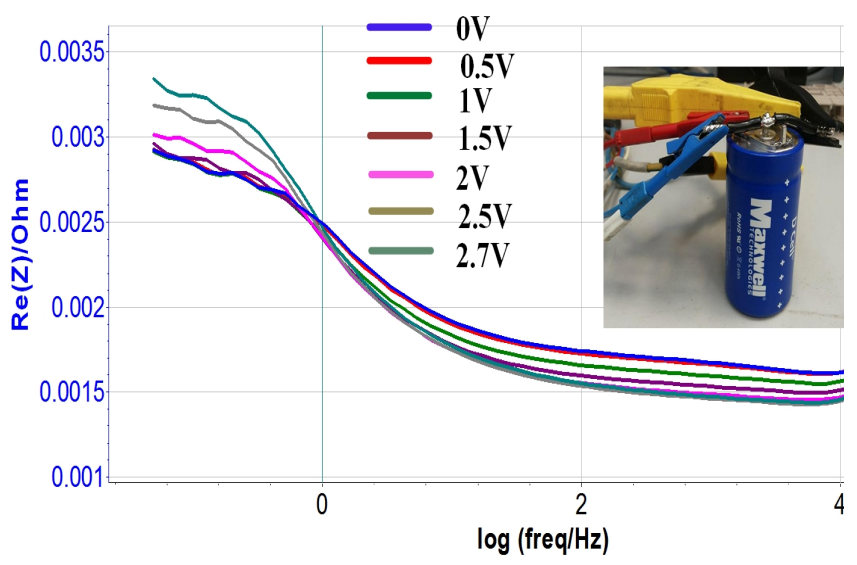

Fig. 6 Electrochemical impedance spectroscopy of SC cell

In order to obtained an accurate model with reasonable complexity, the methodology proposed in [9] has been used by fitting SC-cell's EIS data within a defined targeted frequency range (TFR) selected based on the possible load profiles

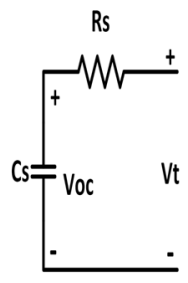

(a)

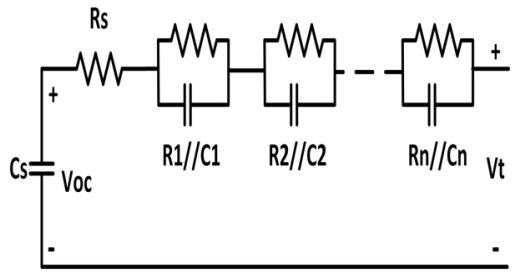

(b)
Fig. 7 Equivalent circuit modelling of SC cell (a) simplified series RC model (b) higher order model

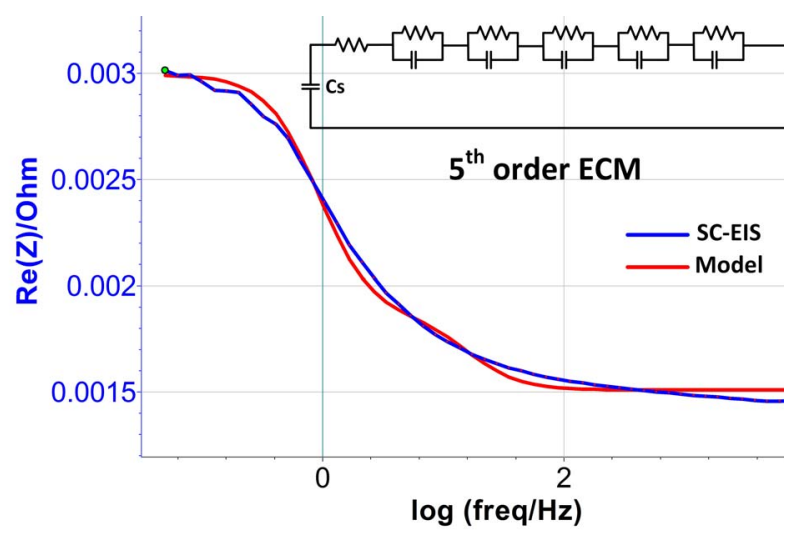

Fig. 8 Fitting SC-cell impedance spectroscopy with $5^{\text {th }}$ order model 


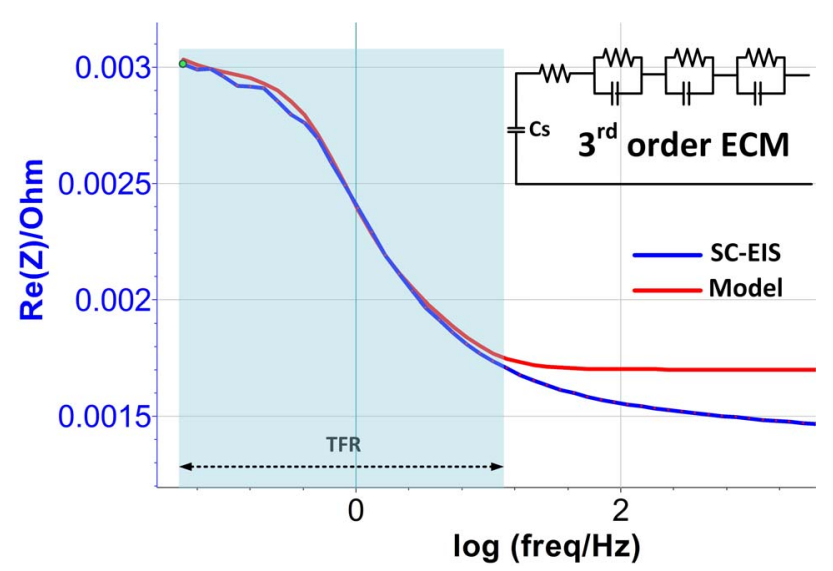

Fig. 9 Fitting SC-cell impedance spectroscopy with $3^{\text {rd }}$ order model

Fig. 9 shows the accuracy of fitting SC-cell EIS with $3^{\text {rd }}$ order ECM within TFR. A similar process has been carried out also for the $150 \mathrm{~F}$ cell which is the choice for the HV$\mathrm{SC}$ unit configuration.

\section{B. Thermal model of SC cells}

The thermal model of the SC-cell can be developed considering the losses due to the ionic and electronic transport and neglecting the losses caused by the thermodynamic phenomena taking place inside the cell [10]. The simplified equivalent circuit (EC) based thermal model can be adapted as in [11] and are illustrated in Fig. 10 , with $R_{\text {cond }}$ representing the resistance for heat transfer by means of conduction inside the $\mathrm{SC}$-cell and $R_{\text {cove }}$ representing the resistance for heat transfer by means of convection between the cell and ambient air and $C_{t h}$ is the thermal capacitance of the SC-cell. To identify the parameters of the thermal model, cycling experiments for the Maxwell 150F cell (used in the HV SC-unit) and 350F cell (used in the LV SC-unit) by constant charge/discharge current under constant ambient temperature were performed followed by a rest period.

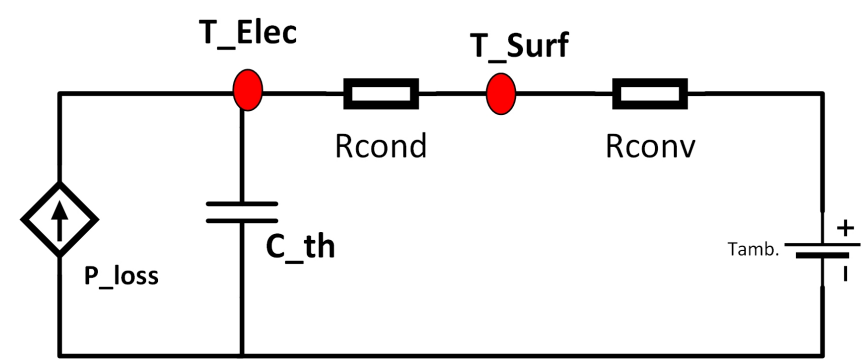

Fig. 10 EC based thermal model of supercapacitor cell

The temperatures of the SC-cells were measured at the electrode terminal (assuming that the thick metal enables fast transfer of internal heat) as an indication of the internal temperature and at surface of the SC-cell by means of thermocouples. The cycling of $t$ he SC-cell were performed for sufficient time to allow reaching a steady state temperature as seen in Fig. 11, where charge/discharge current amplitude was set to $18 \mathrm{~A}$ to produce significant power loss that will result in a sufficient/precisely measurable temperature rise as seen in
Fig. 12. At steady state temperature during cycling, the model parameters $R_{\text {cond }}$ and $R_{\text {conv }}$ can be obtained as:

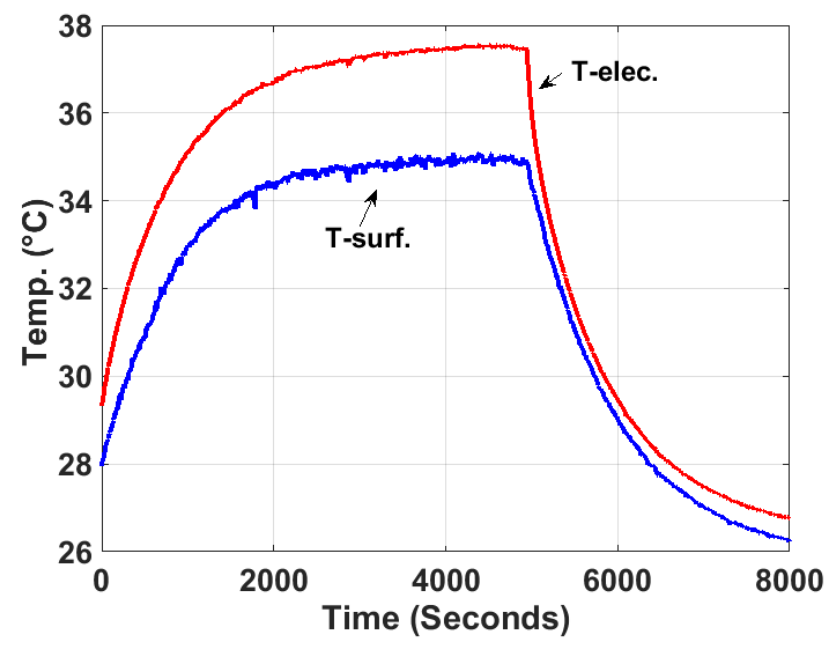

Fig. 11 350F SC-cell electrode and surface temperatures during cycling

$$
\begin{aligned}
R_{\text {cond }} & =\frac{T_{\text {elec }}-T_{\text {surf }}}{P_{\text {loss }}} \\
R_{\text {conv }} & =\frac{T_{\text {surf }}-T_{\text {amb }}}{P_{\text {loss }}}
\end{aligned}
$$

The thermal capacitance can be estimated after identifying the thermal time constant $(\tau)$ of the SC-cell during the rest period as:

$$
C_{t h}=\frac{\tau}{R_{\text {cond }}+R_{\text {conv }}}
$$

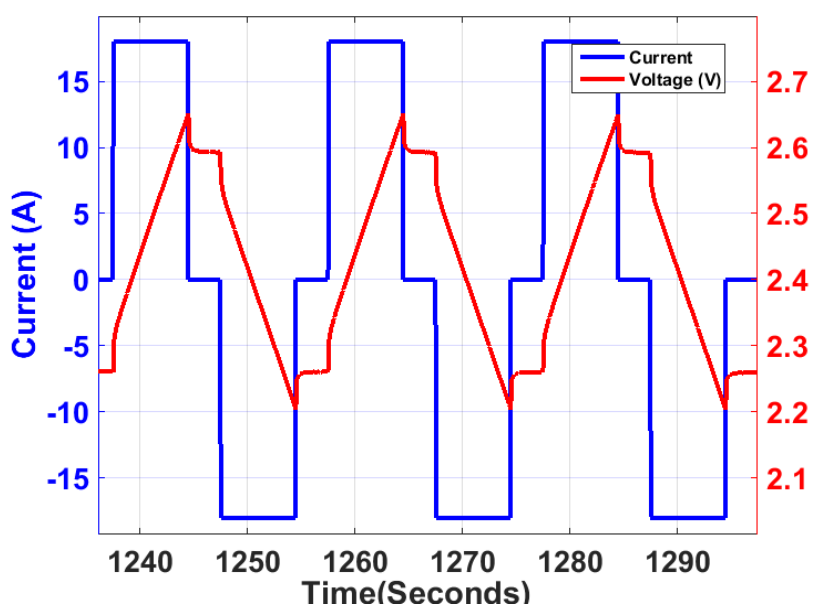

Fig. 12 350F SC-cell current and voltage during charge/discharge cycling

\section{SimUlation RESUTLS}

By using the methodology described in $\S 4 \mathrm{~A}$, the model parameters of the $3^{\text {rd }}$ order ECM have been identified for the Maxwell BCAP0150 (150F) cell as well as Maxwell BCAP0350 (350F) cell by means of curve fitting with the EIS experimental data. The model parameters of both 
candidate SC cells are shown in TABLE 4. Also, thermal model parameters have been obtained for both SC-cells based on cycling experiments as discussed in $\S 4 \mathrm{~B}$. For the $150 \mathrm{~F}$ cell, the thermal conduction resistance $\left(R_{\text {cond }}\right)$, the thermal convection resistance $\left(R_{\text {conv }}\right)$ and thermal capacitance are $3.8{ }^{\circ} \mathrm{C} / \mathrm{W}, 14.5{ }^{\circ} \mathrm{C} / \mathrm{W}$ and $30 \mathrm{~J} /{ }^{\circ} \mathrm{C}$ respectively and for the $350 \mathrm{~F}$ cell, the values of the parameter are $2.5^{\circ} \mathrm{K} / \mathrm{W}, 7.5^{\circ} \mathrm{C} / \mathrm{W}$ and $60 \mathrm{~J} /{ }^{\circ} \mathrm{C}$

TABLE $43^{\text {RD }}$ ORDER MODEL PARAMTERS FOR SC-CELLS

\begin{tabular}{|c|c|c|}
\hline Model parameter & BCAP0150 & BCAP0350 \\
\hline Cs (F) & 150 & 350 \\
\hline $\operatorname{Rs}(\mathrm{m} \Omega)$ & 5.4 & 1.7 \\
\hline C1 (F) & 66 & 202 \\
\hline $\mathrm{R} 1(\mathrm{~m} \Omega)$ & 1.67 & 0.9 \\
\hline $\mathrm{C2}(\mathrm{F})$ & 48.8 & 89 \\
\hline $\mathrm{R} 2(\mathrm{~m} \Omega)$ & 0.7 & 0.3 \\
\hline C3(F) & 3000 & 3000 \\
\hline $\mathrm{R} 3(\mathrm{~m} \Omega)$ & 1 & 2 \\
\hline
\end{tabular}

A simulation model consisted of the $3^{\text {rd }}$ order ECM and thermal model (Fig. 13) with the identified parameters has been built using Simulink ${ }^{\circledR}$ and a load power pulse per cell, equivalent to the $2 \mathrm{~kW}$ system load with duration of 18 seconds has been considered.

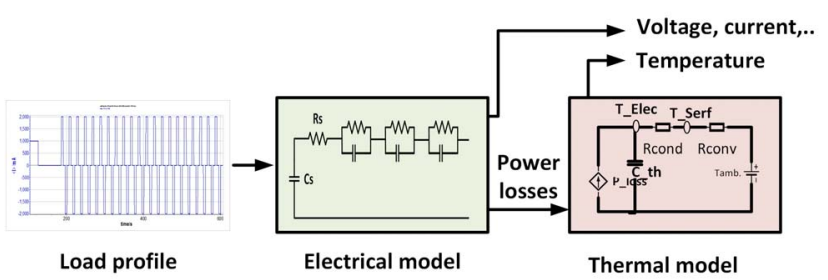

Fig. 13 Block diagram of the developed SC-cell stress model

In order to simulate the performance at the SC-cell level, the load has been scaled down to a single SC-cell according to each SC unit configuration and specific stress. For the LV SC-unit $\left(V_{\max }=110 \mathrm{~V}\right)$ which utilizes 44 series connected SC-cells of BCAP0350 (350F), each cell is to handle $\approx 45 \mathrm{~W}$ constant power pulses during this loading condition. Simulation results from the SC stress model are shown in Fig. 14. The electrical model estimates the power loss of the cell, cell voltage, cell current, instantaneous power loss and cumulated cell energy contribution. It can be noticed that the maximum power loss of the SC-cell is $3.8 \mathrm{~W}$.

Similarly, for the HV SC-unit with $\left(V_{\max }=270 \mathrm{~V}\right)$ which utilizes 104 series connected SC-cells of BCAP0150 ( $150 \mathrm{~F}$ ), each cell is to handle $\approx 19 \mathrm{~W}$ constant power pulses during this loading condition.
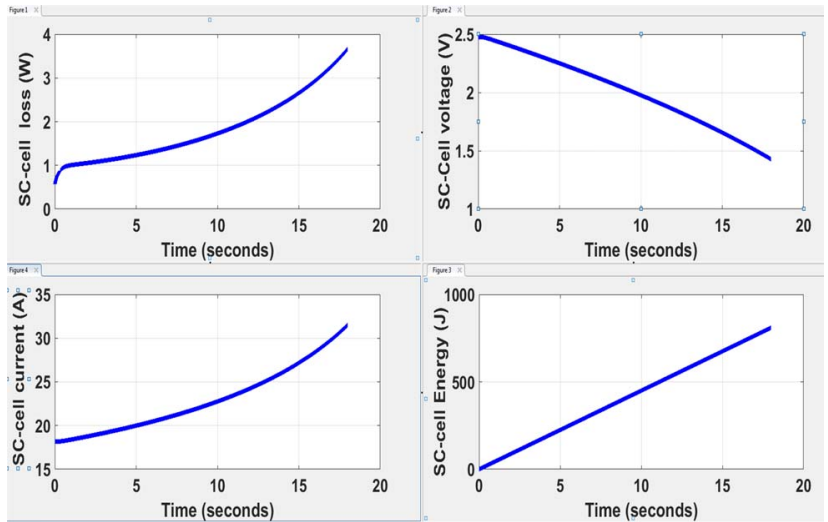

Fig. 14 BCAP0350 SC-cell loss simulation during $2 \mathrm{~kW}$ power loading of the SC-unit

Simulation results from the SC stress model are shown in Fig. 15, with maximum power losses of $2.2 \mathrm{~W}$ for each $\mathrm{SC}$ cell.
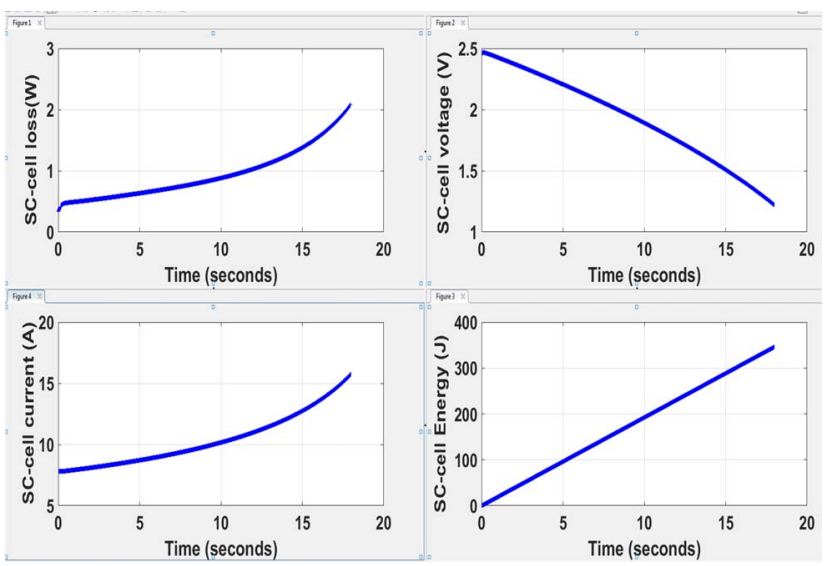

Fig. 15 BCAP0150 SC-cell simulation during $2 \mathrm{~kW}$ power loading of the SC-unit

It can be observed that the power losses of the 350F SCcell in the LV SC-unit design is twice the power loss of the $150 \mathrm{~F}$ cell in the HV SC-unit design.

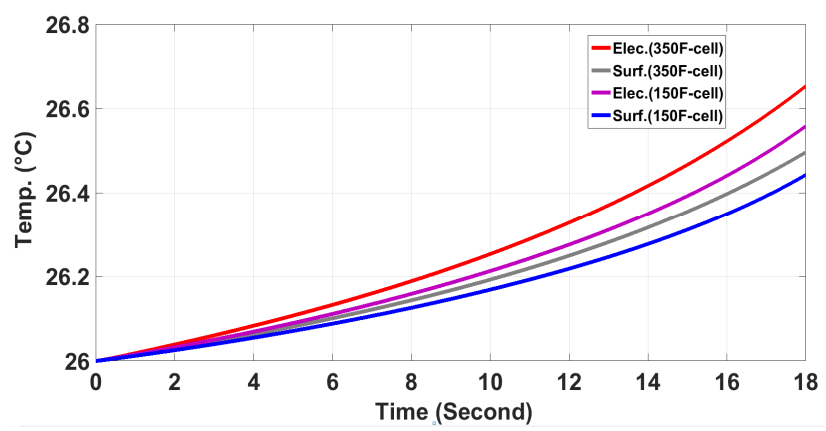

Fig. 16 Temperatures of both $350 \mathrm{~F}$ and $150 \mathrm{~F}$ SC-cell during $2 \mathrm{~kW}$ power loading of the SC-unit

The thermal stresses on both SC-cells are almost same at the end of a single $2 \mathrm{~kW}$ charge/discharge as can be seen in Fig. 16. When designing the cooling, the heating of the 
SC devices during a continuous power cycling may be more relevant. Fig 17 shows that the thermal stress models are able to predict the steady state temperatures of the two SC unit designs: $32^{\circ} \mathrm{C}$ for the internal and $30^{\circ} \mathrm{C}$ for the SC capsule surface for the $150 \mathrm{~F}$ cell and $43^{\circ} \mathrm{C}$ for internal and $39^{\circ} \mathrm{C}$ for surface temperature of the $350 \mathrm{~F}$ cell. Even though the exposure to a continuous power cycle is theoretically possible, it's not to be expected from a real MEA loading but the heating up of both SC devices in this extreme situation is still within the limit which leads to the conclusions that both designs are technically feasible.

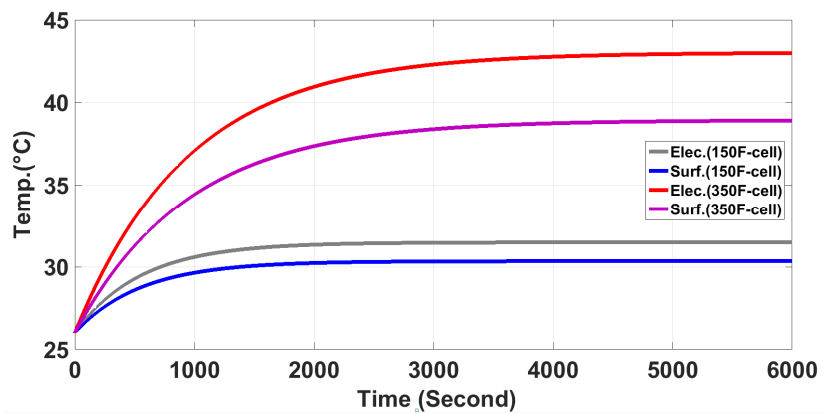

Fig. 17 Temperatures of both $350 \mathrm{~F}$ and 150F SC-cell during continues power cycling of the SC-unit

\section{CONCLUSIONS}

The proposed design technique for a supercapacitor (SC) unit to minimise weight as needed in aircraft applications, achieved $20 \%$ weight reduction compared to a common design technique that would choose $\mathrm{SC}$ devices to maximise converter capability.. Reduction of the SC-unit voltage as a result of having available a significantly energy dense SC device requires an interfacing converter with high boosting ratio which in turns add more weight and results in a reduced system efficiency. However the use of an interleaved topology with superior GaN switches resulted in an insignificant weight penalty for the converter and similar efficiency compared to a converter interfacing with a HV SC-unit which gives best converter design. The thermal stress on the SC-cells due to the higher current requirements under reduced voltage in the LV SC-unit has been investigated.

\section{ACKNOWLEDGMENT}

This work was supported by Egyptian Governmentministry of higher education (cultural affairs and missions sector) $\mathrm{PhD}$ scholarship. The authors also gratefully acknowledge support from the ESTEEM project which received funding from the Clean Sky 2 Joint Undertaking under the European Union's Horizon 2020 research and innovation programme under grant agreement No 755485 .

\section{REFERENCES}

[1] R. Todd, D. Wu, J. A. d. S. Girio, M. Poucand, and A. J. Forsyth, "Supercapacitor-based energy management for future aircraft systems," in 2010 Twenty-Fifth Annual IEEE Applied Power Electronics Conference and Exposition (APEC), 2010, pp. 1306-1312.
[2] W. Zuo, R. Li, C. Zhou, Y. Li, J. Xia, and J. Liu, "BatterySupercapacitor Hybrid Devices: Recent Progress and Future Prospects," Advanced Science, vol. 4, p. 1600539, 2017.

[3] C. K. Mohamed Rashed, "Design and evaluation of an energy storage system forhelicopters," presented at the 9th International Conference on PowerElectronics, Machines and Drives, Liverpool, UK, 2018.

[4] N. Jabbour and C. Mademlis, "Supercapacitor-Based Energy Recovery System With Improved Power Control and Energy Management for Elevator Applications," IEEE Transactions on Power Electronics, vol. 32, pp. 9389-9399, 2017.

[5] Z. Song, H. Hofmann, J. Li, X. Han, and M. Ouyang, "Optimization for a hybrid energy storage system in electric vehicles using dynamic programing approach," Applied Energy, vol. 139, pp. 151-162, 2015/02/01/ 2015.

[6] V. I. Herrera, H. Gaztañaga, A. Milo, A. Saez-de-Ibarra, I. Etxeberria-Otadui, and T. Nieva, "Optimal energy management of a battery-supercapacitor based light rail vehicle using genetic algorithms," in 2015 IEEE Energy Conversion Congress and Exposition (ECCE), 2015, pp. 1359-1366.

[7] J. Klein, "AN-6005 Synchronous buck MOSFET loss calculationswith Excel model " Fairchild applications Bulletin, 2014.

[8] P. Kulsangcharoen, C. Klumpner, M. Rashed, G. Asher, G. Z. Chen, and S. A. Norman, "Assessing the accuracy of loss estimation methods for supercapacitor energy storage devices operating under constant power cycling," in 2014 16th European Conference on Power Electronics and Applications, 2014, pp. 1-11.

[9] A. M. Fares, C. Klumpner, and M. Sumner, "Development of a battery energy loss observer based on improved equivalent circuit modelling," in 2016 18th European Conference on Power Electronics and Applications (EPE'16 ECCE Europe), 2016, pp. 1-10.

[10] P. Guillemet, Y. Scudeller, and T. Brousse, "Multi-level reduced-order thermal modeling of electrochemical capacitors," Journal of Power Sources, vol. 157, pp. 630-640, 2006/06/19/ 2006.

[11] A. Hijazi, P. Kreczanik, E. Bideaux, P. Venet, G. Clerc, and M. D. Loreto, "Thermal Network Model of Supercapacitors Stack," IEEE Transactions on Industrial Electronics, vol. 59, pp. 979-987, 2012. 